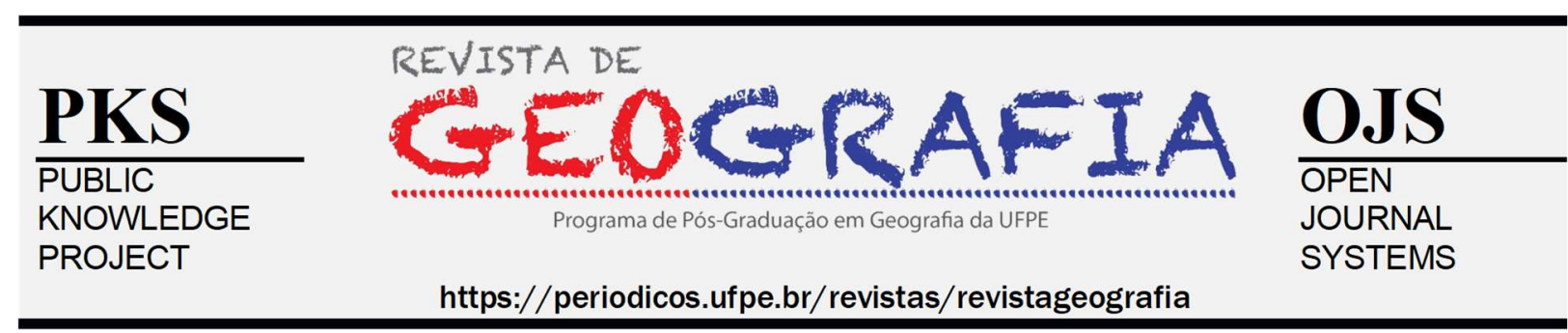

\title{
MAPEAMENTO E ANÁLISE DOS NÍVEIS DE SEVERIDADE DE ÁREAS DE QUEIMADAS NO SEMIÁRIDO BRASILEIRO COM O USO DE TÉCNICAS DE GEOPROCESSAMENTO
}

\author{
Eurides Ferreira de Alcântara ${ }^{1}$, Renato de Oliveira Fernandes² \\ ${ }^{1}$ Universidade Regional do Cariri, E-mail: eurides.f.a@gmail.com, ORCID: orcid.org/0000-0002-2726-1695 \\ ${ }^{2}$ Universidade Regional do Cariri, E-mail: renatodeof@gmail.com, ORCID: orcid.org/0000-0001-5169-2324
}

Artigo recebido em 11/05/2020 e aceito em 17/11/2020

\begin{abstract}
RESUMO
O conhecimento da abrangência das queimadas bem como sua severidade são fatores essenciais para mensurar os diferentes impactos ambientais, especialmente sobre o clima. Em regiões semiáridas, como no Nordeste Brasileiro, devido às características específicas da vegetação, o mapeamento das queimadas apresenta grandes desafios. O presente trabalho tem como objetivo mapear a extensão e o grau de severidade de queimadas ocorridas na microbacia hidrográfica do Riacho do Barriga, localizada no município de Farias Brito na Região Metropolitana do Cariri no semiárido cearense, no período de 01 de setembro a 31 de outubro de 2019, empregando técnicas de geoprocessamento por meio da aplicação do RBR (relativized burn ratio) calculado com base no NBR (Normalized Burn Ratio) pré e pós incêndio, utilizando imagens do sensor MSI (MultiSpectral Instrument ) embarcado no satélite sentinel-2. Os resultados obtidos mostraram que cerca de metade da área em estudo foi acometida por queimadas (1.045,05 ha), com níveis de severidade de baixa (29,5\%) a moderada (20,6\%). O RBR mostrou-se uma ferramenta importante na delimitação e caracterização de queimadas, superestimando as áreas de queimadas em $8,2 \%$ e subestimando em 7,2\% às áreas não queimadas.
\end{abstract}

Palavras-chave: Índice de queimada normalizada; Geotecnologias; Satélite sentinel-2; Mapa de queimadas

\section{MAPPING AND ANALYSIS OF FIRE SEVERITY LEVELS USING GEOPROCESSING IN THE BRAZILIAN SEMI-ARID}

\begin{abstract}
Knowledge of the extent of fires as well as their severity are essential factors in measuring their environmental impacts, especially on the climate. In semiarid regions, such as in NE Brazil, the mapping of fires presents great challenge due to the vegetation characteristics. This study aims to map the extent and severity of fires in the Riacho do Barriga watershed, located in Farias Brito in the Metropolitan Region of Cariri in the semiarid region of Ceará, from September 1 to October 31 of 2019. The study employs remote sensing techniques through the application of the relativized burn ratio (RBR), calculated based on the normalized burn ratio of pre- and postfire conditions using images from a multi-spectral instrument sensor embedded in the Sentinel-2 satellite. Results showed that approximately half of the study area (1,045.05 ha) was affected by fires with levels of severity ranging from low $(29.5 \%)$ to moderate $(20.6 \%)$. The RBR proved to be an important tool in the delimitation and characterization of fires by overestimating the areas under fires by $8.2 \%$ and underestimating the areas not burned by $7.2 \%$.
\end{abstract}

Keywords: Normalized burn ratio; Geotechnology; Sentinel-2 satellite; Fire map 


\section{INTRODUÇÃO}

O processo de desmatamento é muito utilizado por pequenos e médios produtores rurais, principalmente em regiões onde o conhecimento técnico ainda é precário, avançando por novas áreas e mudando os cenários da vegetação. Decorrente desses desmatamentos estão as queimadas de biomassa, método muito utilizado para limpeza rápida de áreas a serem cultivadas, devido seu baixo custo e rapidez no processo.

No entanto, essas queimadas não destroem apenas as áreas desmatadas para essa finalidade, infelizmente muitas das vezes por negligência ou imperícia, o fogo ultrapassa para áreas de floresta gerando uma verdadeira cadeia de incêndios. Embora essa não seja a única maneira de propagação de incêndios é a que tem gerado os maiores incêndios florestais no Brasil (MORAIS, 2011).

A intensidade ou severidade das queimadas está diretamente relacionada com os processos de degradação do solo como perdas por erosão e desequilíbrio na oferta de nutrientes o que pode ocasionar o comprometimento da capacidade de regeneração da biodiversidade (CAPECHE, 2012). Para Bertani (2014) a severidade de queima representa um fator indicativo dos possíveis efeitos do fogo sobre a cobertura vegetal e o solo.

As queimadas contribuem para o agravamento das mudanças climáticas (IPCC, 2019) devido a emissão dos gases que causam o efeito estufa. No Brasil, no ano de 2018 , o desmatamento foi responsável por $44 \%$ dos gases que causam o aquecimento do planeta (SEEG, 2020). Nesse mesmo ano, o Brasil foi o segundo país que mais emitiu $\mathrm{CO}_{2}$ da América Latina, ficando atrás apenas do México, e o décimo quarto país no mundo.

De acordo com Vedovato (2015) quantificar o tamanho da região queimada é de extrema necessidade para mensurar as proporções do impacto causado pelos incêndios. A estimativa dessas áreas de severidade em campo seria um trabalho com alta demanda de tempo e recursos, considerando a possibilidade de recobrir extensas áreas e a dificuldade de acesso.

Diante disso, o sensoriamento remoto pode fornecer dados capazes de subsidiar essa análise, Melo (2015) afirma que essa técnica pode fornecer dados capazes de subsidiar interpretação e mensuração as dinâmicas geográficas, possibilitando análises multitemporais dos fenômenos que provocam alterações no espaço geográfico. Concordando com a mesma ideia Florenzano (2011), aponta que o sensoriamento remoto pode ser usado para detectar 
focos de calor, informações sobre temperatura, mensurar cicatriz de queimadas recentes e antigas, além de acompanhar o processo de recuperação.

O uso dos sensores multiespectrais e hiperespectrais de média resolução espacial tem se consolidado em estudos de detecção de áreas acometidas com processo de queimadas (ex. SILVA e BAPTISTA, 2015; FOLHARINI, VIEIRA e BENTO-GONÇALVES, 2018; KEELEY, 2009).

Dentre as principais metodologias usadas para obtenção de informações sobre áreas queimadas está o índice de queimada normalizada (NBR - Normalized Burn Ratio), que procura destacar regiões queimadas usando como base a resposta espectral da vegetação sadia, fotossinteticamente ativa, em contraste com a afetada pelas chamas (KEY e BENSON, 1999).

Para estudos de severidade a diferença do índice de queimada normalizada (dNBR Differenced Normalized Burn Ratio) proposto por Roy, Boschetti e Trigg (2006) é comumente empregado, no entanto, algumas pesquisas apontam uma dificuldade na detecção de mudanças quando a imagem pré-incêndio apresenta baixa cobertura vegetal (RIBEIRO e BAPTISTA, 2015; ROSAN e ALCANTARA, 2015; BERTANI, 2014).

Pensando em minimizar esse problema, Parks, Dillon e Miller (2014) propuseram uma relativização do dNBR, projetada para detectar mudanças mesmo quando a cobertura vegetal antes do incêndio é baixa, o índice de queima relativizada (RBR).

Este índice, por estar menos relacionados com o NBR pré-incêndio, detecta melhor as mudanças mesmo com cobertura vegetal baixa, comum no semiárido brasileiro, melhorando a detecção de efeitos de severidade em toda a faixa de cobertura vegetal préincêndio.

Desta forma, o presente trabalho busca por meio de técnicas de geoprocessamento, delimitar e caracterizar, de acordo com o grau de severidade, as áreas de queimadas ocorridas na microbacia hidrográfica do Riacho do Barriga, localizada no município de Farias Brito, Ceará, no segundo semestre de 2019.

\section{METODOLOGIA}

Área de estudo

A área de estudo (Figura 1) compreende a microbacia hidrográfica do Riacho do Barriga, localizada no município de Farias Brito na Região Metropolitana do Cariri cearense, 
cobrindo uma área de aproximadamente 2.082,87 ha, geolocalizada entre as coordenadas $6^{\circ} 55^{\prime} 00.2^{\prime \prime}$ e 6 $50^{\prime} 48.2^{\prime \prime}$ Sul e $39^{\circ} 35^{\prime} 59.6^{\prime \prime}$ e 39³3'34.0" Oeste.

A microbacia situa-se na encosta da serra do Quincuncá, região de relevo predominantemente irregular variando de fortemente ondulado para montanhoso, com alguns pontos de terreno escarpado de acordo com a classificação de Lepsch (1991 apud Gallo e Oliveira Junior, 2010). As características climáticas da região segundo a classificação de Koppen-Geiger são do tipo Bsh (clima semiárido quente), com média pluviométrica de 955,3 mm/ano (FUNCEME, 2020).

Como todo o município está inserido no bioma caatinga (IPECE, 2018) a cobertura vegetal da área de estudo apresenta a mesma característica. O solo, de acordo com Santos et al. (2011) é classificado como neossolos litólico, descrito por EMBRAPA (2018) como de baixa capacidade de infiltração e armazenamento de água, baixa aptidão agrícola e alta suscetibilidade à erosão. A área da microbacia é fracionada em pequenas e médias propriedades rurais caracterizadas pela produção agropecuária com pouca adoção de tecnologias.

Figura 1 - Bacia Hidrográfica do Riacho do Barriga, CE 2020.

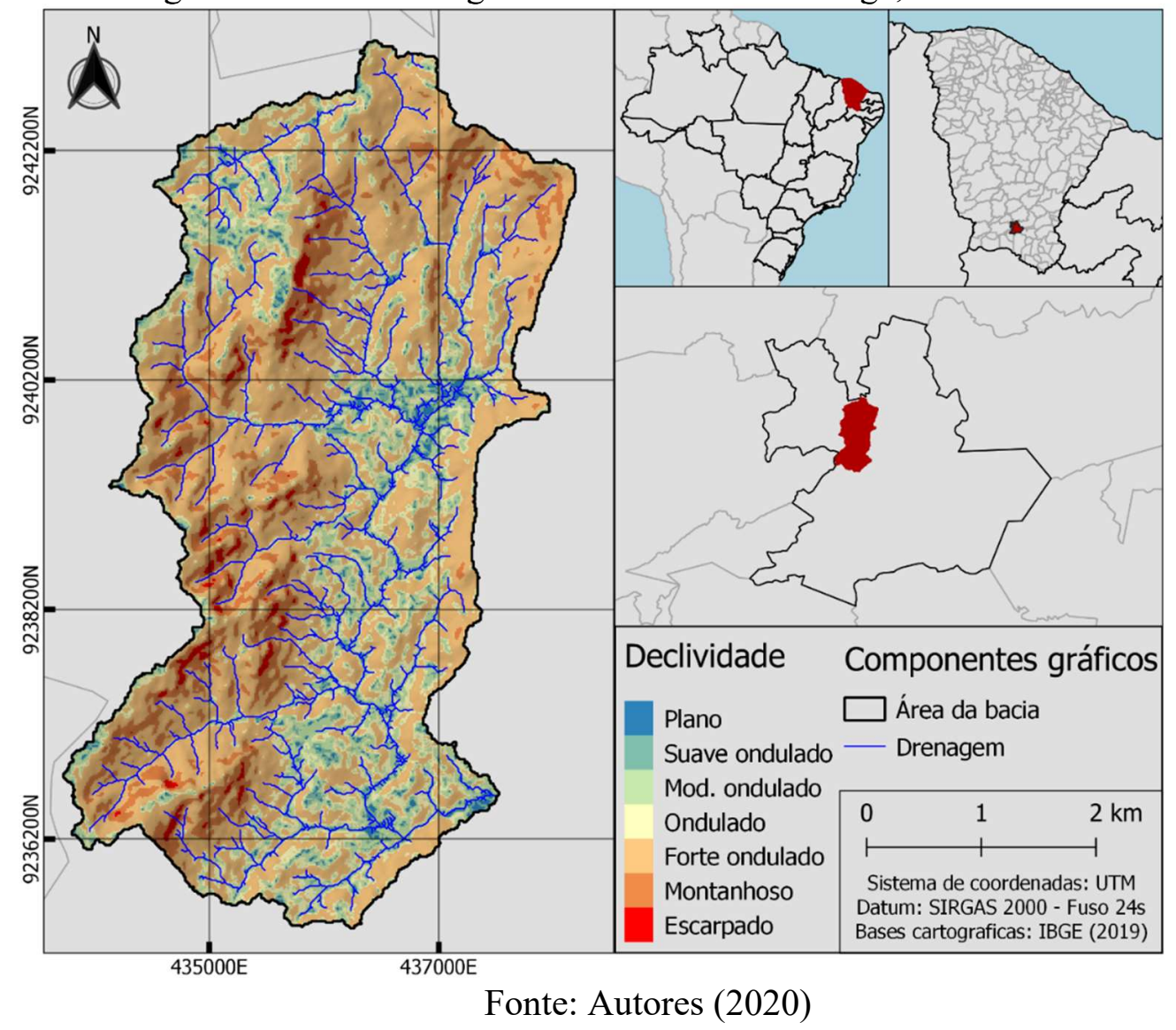


Coleta e processamento de dados

A metodologia utilizada toma como base os parâmetros espectrais derivados dos produtos dos sensores multiespectrais com validação do mapeamento das queimadas através da classificação supervisionada. As imagens utilizadas são provenientes do sensor MultiSpectral Instrument (MSI) da missão Copernicus Sentinel-2, e foram obtidas através do catálogo do Copernicus Access Open Hub (2020) da plataforma online da European Space Agency (ESA, 2020).

Os critérios de escolha levaram em consideração a cobertura de nuvem, a representação da área de estudo e a variação temporal das imagens de modo que as datas de obtenção fossem antes e após a ocorrência das queimadas noticiadas pela imprensa (CEARÁ..., 2019), em 01 de setembro de 2019 e 31 de outubro de 2019, respectivamente. As imagens selecionadas foram da cena 24MVT e as bandas utilizadas foram as B08 (NIR) infravermelho próximo e B12 (SWIR2) referente ao infravermelho médio. Ambas as cenas foram obtidas em nível 2A, reflectância de fundo de atmosfera. Devido à diferença de resolução espacial das imagens foi necessário a reamostragem de pixels das bandas B12 de 20 $\mathrm{m}$ para $10 \mathrm{~m}$, processo este que foi realizada por interpolação bilinear.

A disposição do terreno ao receber os raios solares pode gerar alterações na reflectância da superfície e, dependendo do seu ângulo de incidência, é capaz de realçar esses valores em áreas ensolaradas ou diminuir em áreas sombreadas (SILVA e VALERIANO, 2005). Devido a esse problema e considerando o relevo montanhoso da região de estudo foi aplicado o modelo de correção topográfica de Minnaert (LAW e NICHOL, 2004), visando minimizar os efeitos da posição de incidência de raios solares nas superfícies irregulares.

Foi realizado ainda a normalização radiométrica devido à necessidade de observar a variação temporal da reflectância pelos índices utilizados (PONZONI; SHIMABUKURO e KUPLICH, 2012), sendo efetuada a seleção de pontos claros e escuros ao longo da cena caracterizados pela baixa ou nenhuma variação da reflectância ao longo do período de estudo.

Após o pré-processamento foram calculados os Índice de Queima Normalizada (NBR) para os dois recortes temporais selecionados, conforme proposto por Key e Benson (1999). Esse procedimento baseia-se no contraste existente entre as bandas infravermelho próximo e médio devido sua diferente resposta espectral entre áreas fotossinteticamente ativas e áreas carbonizadas. 
O grau de severidade das queimadas foi obtido através do cálculo do RBR (índice de queima relativizada), que consiste na relativização da diferença dos dados de NBR (Índice de Queima Normalizada) pré-fogo e NBR pós-fogo, conforme Parks, Dillon e Miller (2014).

Para a representação da severidade das queimadas, foi aplicada o padrão de classificação descrito na Tabela 1 sugerido por Key e Benson (2006).

Tabela 1 - Níveis de Severidade para variações do RBR

\begin{tabular}{lcc}
\hline Nível de Severidade & Variação do RBR & Cor \\
\hline Não queimado & $<0.99$ & \\
Baixa Severidade & 0.100 a 0.269 \\
Moderada Baixa Severidade & 0.270 a 0.439 \\
Moderada Alta Severidade & 0.440 a 0.659 \\
Alta Severidade & 0.660 a 1.300 \\
Corpo de água & - \\
\hline
\end{tabular}

Fonte: Key e Benson (2006), adaptado

Para validação da metodologia foi feita a classificação supervisionada na cena pósincêndio utilizando o classificador do modelo de mistura gaussiana (MMG) (FAUVEL et al., 2015) aplicando o algoritmo desenvolvido por Karasiak (2016), sendo posteriormente empregada uma edição manual para representar o máximo possível da realidade. Essa classificação foi utilizada como verdade de campo para calcular a matriz de confusão para o coeficiente de concordância Kappa (COHEN, 1960).

Foram calculados ainda os dados de omissão, áreas que deveriam ser classificadas como "Queimadas" e resultaram em "Não Queimadas”, e comissão, áreas que deveriam ser classificadas como "Não Queimadas" e resultaram em "Queimadas, ambas com base na classificação atribuída como verdade de campo calculados por meio de álgebra de raster aplicando a diferença dos dois resultados.

Devido sua baixa reflectância, os corpos de água em determinadas circunstâncias podem gerar confusão com queimadas no índice NBR. Para mitigar esse problema foi gerada, o índice de diferença normalizada da água (NDWI - Normalized Difference Water Index) (GAO, 1996), em seguida editado com base em fotointerpretação para retirar possíveis falha na cobertura, e usado como máscara de corpos de água sendo esta aplicada em toda extensão do raster de RBR e da classificação supervisionada. 


\section{RESULTADOS E DISCUSSÃO}

Os resultados obtidos para o RBR com aplicação do fatiamento de classes e indicação dos níveis de severidade para bacia hidrográfica do Riacho do Barriga, CE, estão mostrados na Figura 2.

Figura 2 - Mapeamento das áreas de queimadas e níveis de severidade para a Bacia Hidrográfica do Riacho do Barriga, CE (01/09 a 31/10/2019).

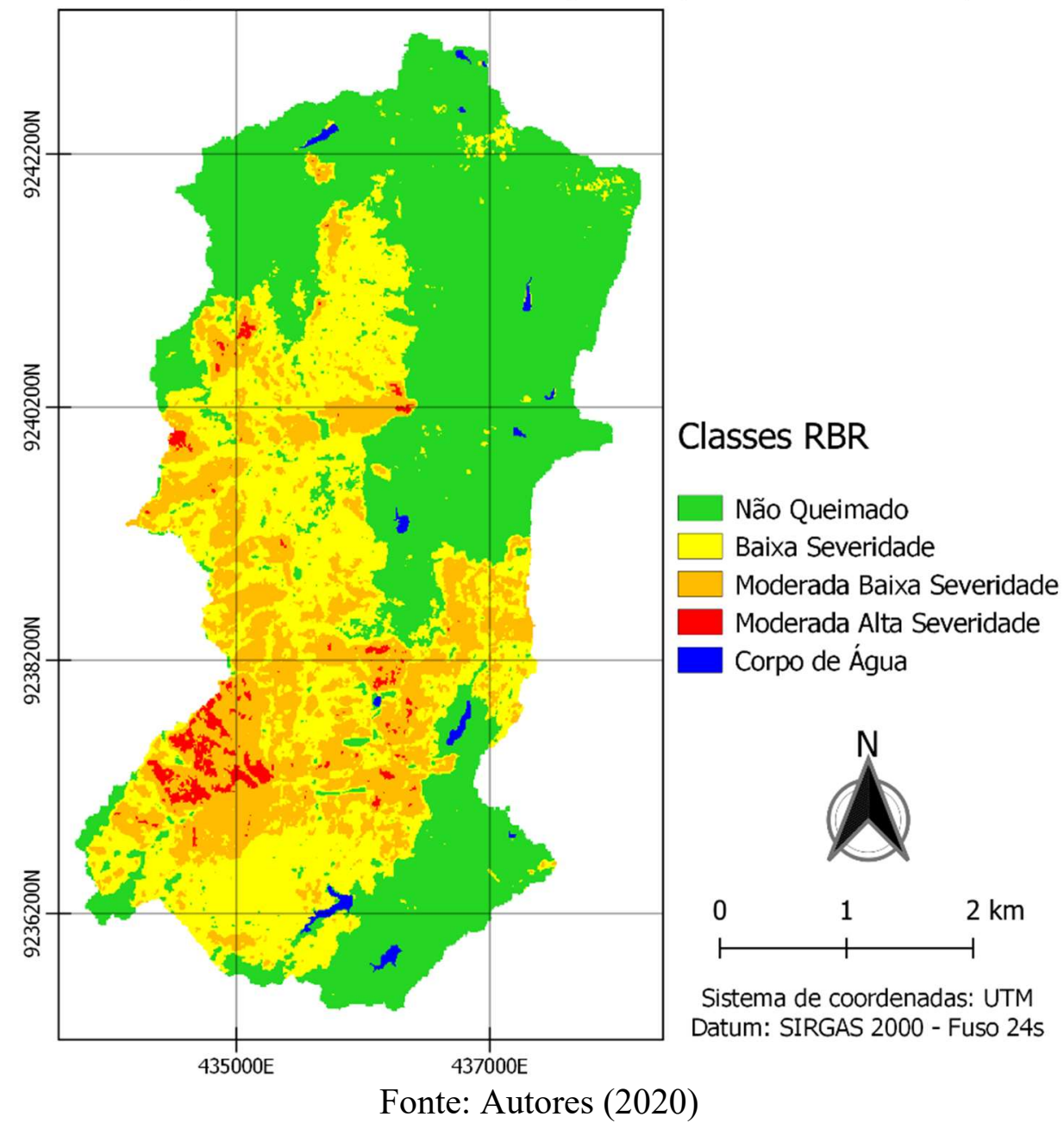

Observa-se que uma grande extensão da bacia sofreu com a incidência de incêndios.

Foi estimado, de acordo com o limiar de classificação de queimadas, que cerca da metade da área total da microbacia $(50,17 \%)$ apresenta áreas carbonizadas. Porém, a maior parte $(29,47 \%)$ apresenta baixa severidade e as demais porcentagens $19,19 \%$ e $1,51 \%$ moderada de baixa e alta severidade, respectivamente, sendo essas predominantes em terrenos com topografia com alta declividade.

O mapeamento da área queimada na microbacia do Riacho do Barriga permitiu identificar mais de 1.045,05 ha de queimadas no período de 01 de setembro de 2019 a 31 de 
outubro de 2019. Além disso, é possível observar que a grande maioria destes focos se encontram nas regiões com declive mais acentuado, o que condiz com as características apontadas por Flores, Ornelas e Dias (2016) onde é informado que terrenos mais íngremes facilitam a propagação das chamas pelo efeito da convecção e radiação sobre os combustíveis não queimados e influencia a ação de combate ao fogo.

Corrobora com isso o fato das áreas que apresentaram os mais elevados níveis de severidade de queimadas (Figura 2) estarem localizadas em pontos com declividade variando de forte ondulado, montanhoso e escarpado (Figura 1).

Os quantitativos de áreas de acordo com a classificação de severidade das queimadas estão apresentados na Tabela 2.

Tabela 2 - Quantitativos de áreas queimadas por índice de severidade para a bacia.

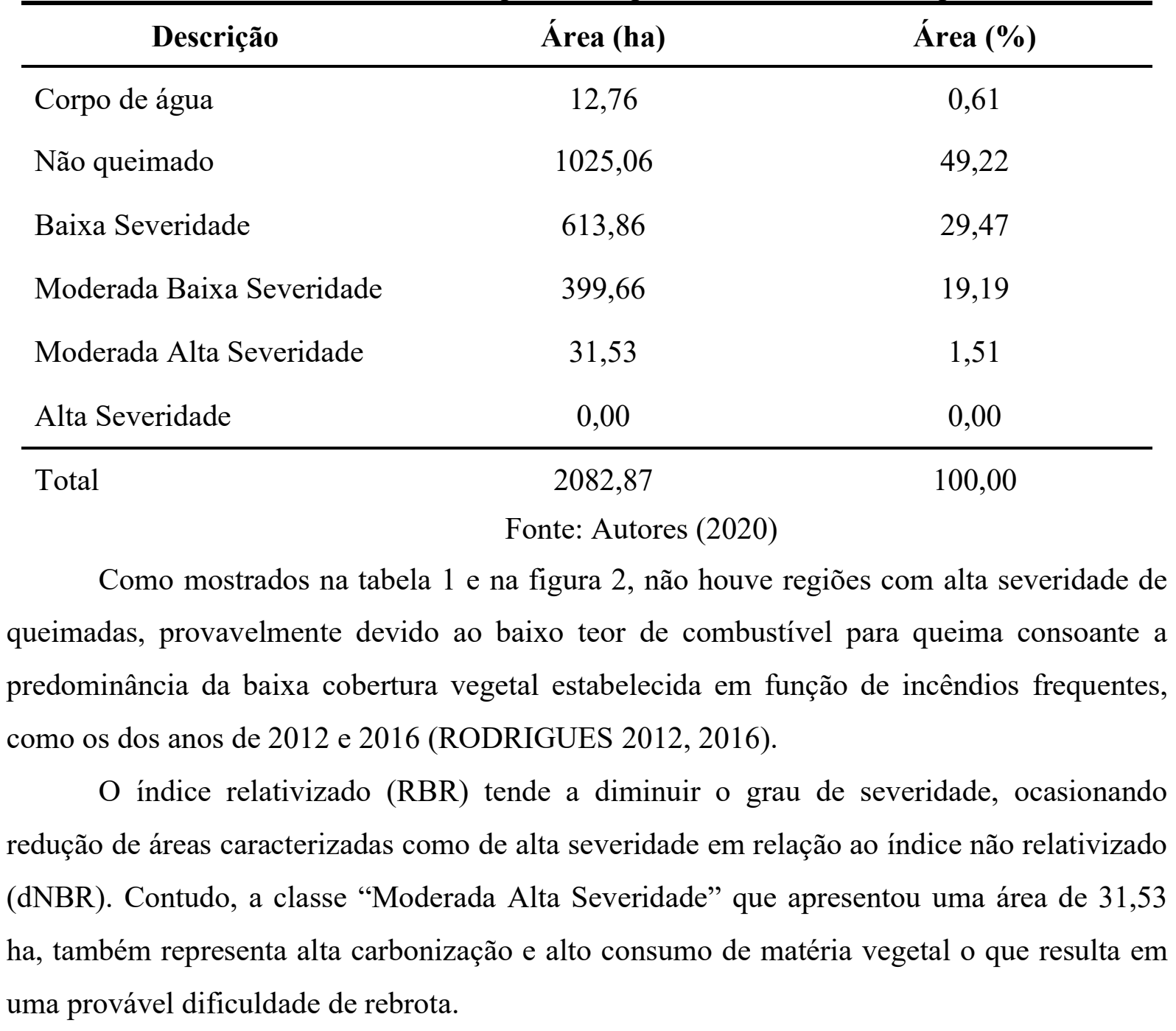


$\mathrm{Na}$ figura 3 é apresentado o comparativo das queimadas estimadas pelo índice de queima e pela classificação supervisionada MMG. Visualmente as áreas são espacialmente compatíveis, embora o índice RBR ter superestimado algumas áreas.

Figura 3 - Comparação da estimativa de área queimada obtida pelo índice de queima RBR (a) e pela classificação supervisionada MMG (b) para a Bacia Hidrográfica do Riacho do Barriga,
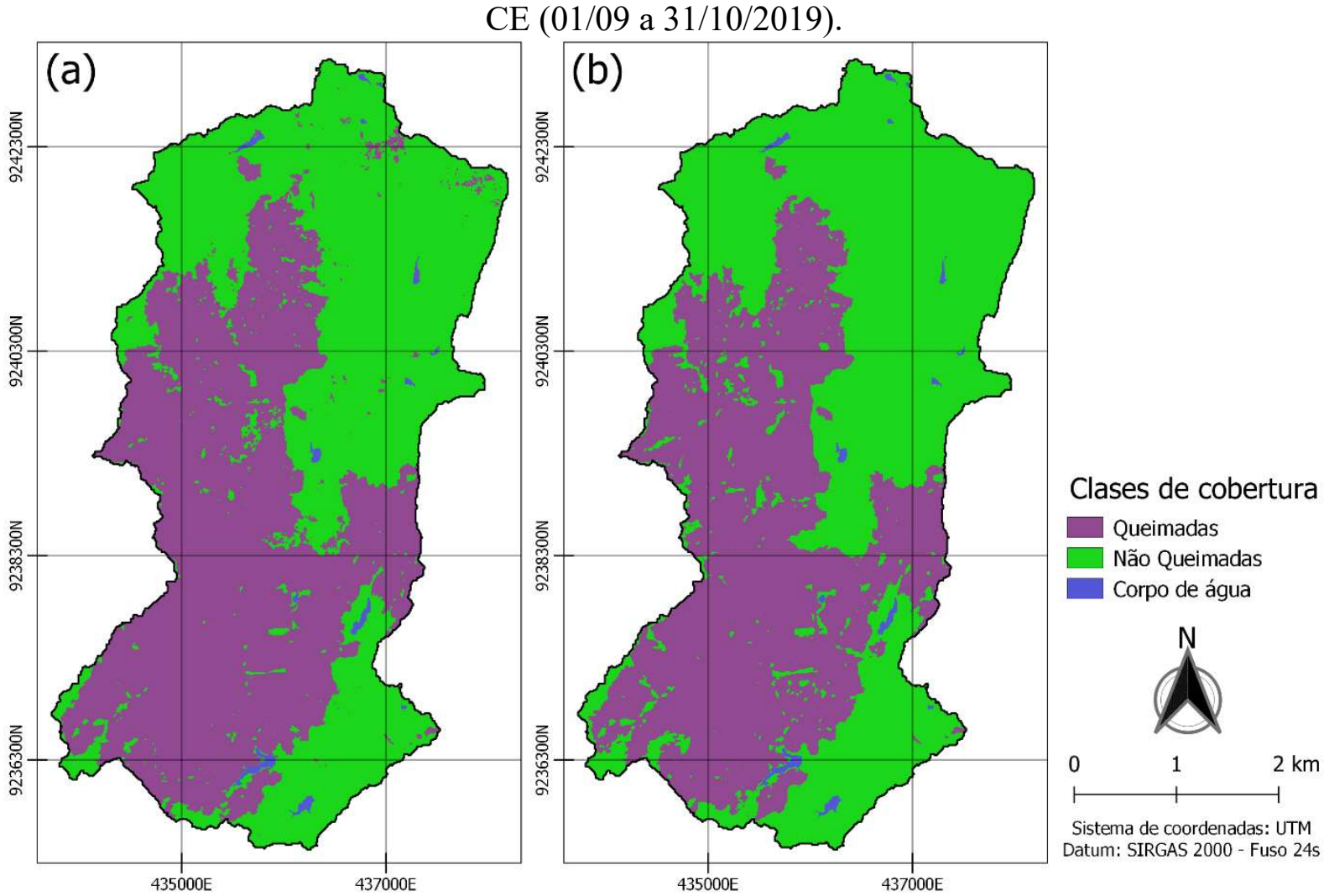

Fonte: Autores (2020)

Para validar a acurácia da estimativa foi calculada a matriz de confusão entre a imagem raster gerada pelo RBR e o pela classificação supervisionada, sendo esta última tomada como referência de campo pela sua acurácia, mas que por outro lado demanda mais tempo de classificação por o procedimento não ser executado de forma automática.

O valor do coeficiente Kappa para a correlação foi de 0,90, que é considerado excelente (LANDIS e KOCH, 1977). Além disso, foi obtido também uma correspondência de aproximadamente $95 \%$ de exatidão na comparação pixel a pixel entre o resultado alcançado pelo índice RBR e pela classificação MMG.

A análise dos resultados obteve os erros de omissão e comissão de aproximadamente 1,20\% e 8,79\%, respectivamente. Em síntese, os erros de comissão estão situados nas bordas da queimada e regiões que possuíam elevado índice foliar pré-incêndio que, neste caso, devido às características climáticas da região, houve perda de área foliar em comparação com 
o período pós-incêndio. Por outro lado, os erros de omissão são, predominantemente, resultantes de regiões com baixa cobertura vegetal pré-incêndio, dificultando o contraste com a reflectância pós-incêndio. Os quantitativos de áreas calculadas pelos dois métodos estão apresentados na Tabela 3 .

Tabela 3 - Comparação das áreas estimadas pelo RBR e pela classificação supervisionada.

\begin{tabular}{lccc} 
& RBR (ha) & Classificação (ha) & Variação (\%) \\
\hline Queimada & 1045,05 & 965,75 & 8,2 \\
Não queimada & 1025,06 & 1104,36 & $-7,2$ \\
Corpos de água & 12,76 & 12,76 & 0,0 \\
\hline Total & 2082,87 & 2082,87 & -
\end{tabular}

A figura 4 ilustra as dimensões do incêndio ocorrido na área de estudo do presente trabalho, nela podemos perceber as condições topográficas, já descridas, bem como as proporções do evento estudado.

Figura 4 - Queimadas no município de Farias Brito, Ceará, (17 de setembro de 2019).
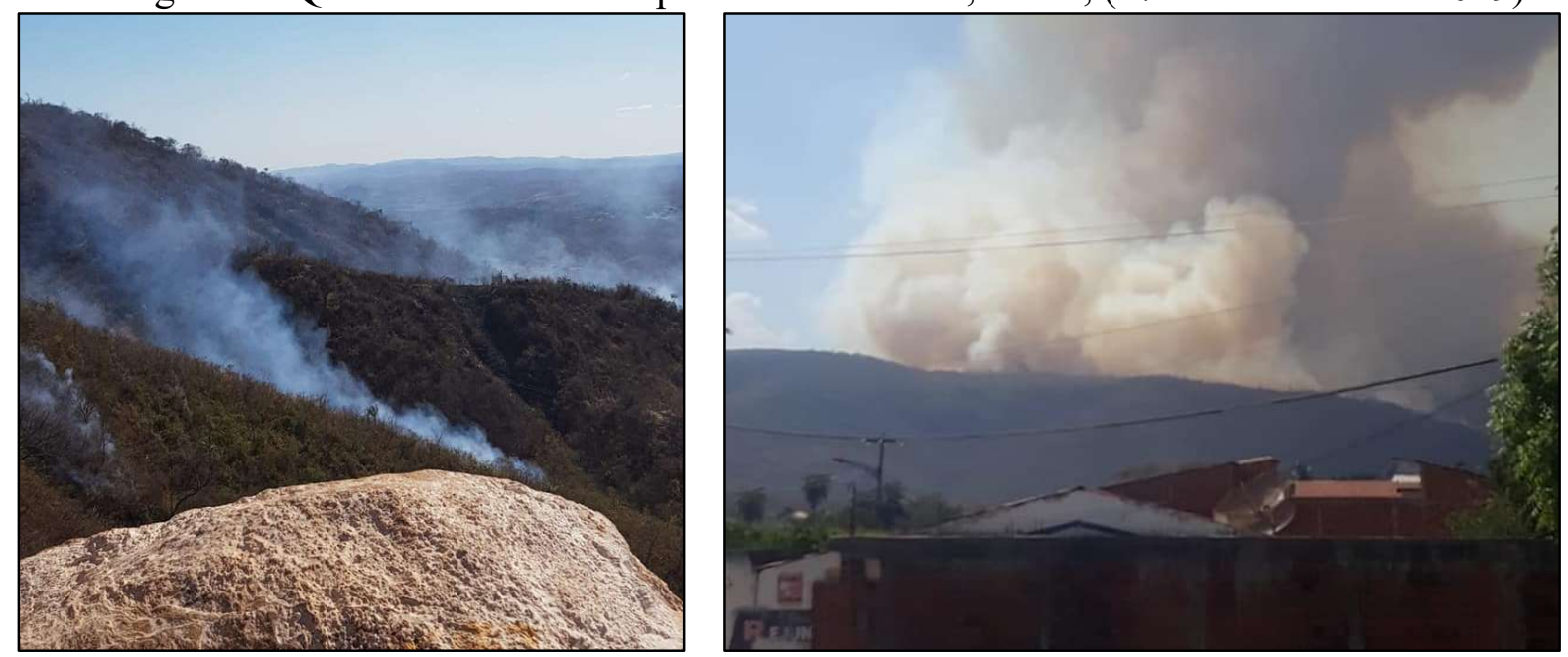

Fonte: Farias Brito News (2019), adaptado

\section{CONCLUSÃO}

A metodologia empregada mostrou-se adequada para estimar às áreas de queimadas e a espacialização dos níveis de severidade, especialmente se considerarmos as dificuldades de acesso, custos financeiros e de tempo para estudos de campo em toda a região afetada. 
As mudanças bruscas na cobertura vegetal causadas por outros fatores além das queimadas, como por exemplo, o desmatamento ou a caducidade das folhas, característica do bioma caatinga no segundo semestre do ano, podem influenciar na resposta espectral provocando a superestimação do RBR, que foi identificado como sendo de $8,2 \%$ através da classificação supervisionada.

Foi possível concluir também que as queimadas na microbacia hidrográfica do Riacho do Barriga, foram predominantes em terrenos com topografia com alta declividade. $\mathrm{O}$ que reforça a influência desse cenário na velocidade de propagação e nas condições de combate ao sinistro.

Recomenda-se que em pesquisas posteriores sejam analisados dados coletados após o período chuvoso para avaliar a recuperação da área afetada e estimar a rebrota, melhorando assim a compreensão da severidade do incêndio.

\section{REFERÊNCIAS}

BERTANI, Gabriel. Determinação de áreas queimadas e severidade de queima a partir da análise de autocorrelação espacial. 2014. Disponível em: https://bit.ly/3aWDTTI. Acesso em: 14 abr. 2020.

CAPECHE, Claudio Lucas. Impactos das queimadas na qualidade do solo: degradação ambiental e manejo e conservação do solo e água. In: ENCONTRO CIENTÍFICO DO PARQUE ESTADUAL DOS TRÊS PICOS, 2., 2012, Cachoeiras de Macacu. Anais [...]. Rio de Janeiro: Inea, 2012. p. 17-20. Disponível em: https://bit.ly/2D0Nc9Z. Acesso em: 23 jul. 2020.

CEARÁ registra 85 ocorrências de incêndio em 9 cidades no mês de setembro. Diário do Nordeste, Fortaleza, p. 1-2, 21 set. 2019. Disponível em: https://bit.ly/338LP3N. Acesso em: 28 jul. 2020.

COHEN, Jacob. A Coefficient of Agreement for Nominal Scales. Educ. Psychol. Meas., [S.L.], v. 20, n. 1, p. 37-46, abr. 1960.

EMBRAPA. Sistema Brasileiro de Classificação de Solos. 5. ed. rev. e aum. Brasília: Embrapa, 2018. 356 p. ISBN 978-85-7035-800-4.

ESA - European Space Agency. Copernicus Open Access Hub. 2020. Disponível em: https://scihub.copernicus.eu/dhus/\#/home. Acesso em: 15 abr. 2020. 
FARIAS BRITO NEWS. A Serra do Quincuncá e regiões vizinhas pede socorro! Fogo toma conta e destrói vegetação. Farias Brito, 17 set. 2019. fotografia. Disponível em: https://bit.ly/30f0qZQ. Acesso em: 30 jul. 2020.

FAUVEL, Mathieu et al. Fast Forward Feature Selection of Hyperspectral Images for Classification With Gaussian Mixture Models. IEEE Journal, New York, v. 8, n. 6, p. 28242831, jun. 2015. DOI 10.1109/JSTARS.2015.2441771.

FLORENZANO, Tereza Gallotti. Iniciação em sensoriamento remoto. 3. ed. atual. e aum. São Paulo: Oficina de Textos, 2011. 123 p. ISBN 978-85-7975-016-8.

FLORES, Bráulio Cançado; ORNELAS, Éliton Ataíde; DIAS, Leônidas Eduardo. Fundamentos de Combate a Incêndio: Manual de Bombeiros. Corpo de Bombeiros Militar do Estado de Goiás. Goiânia-GO, 1ed: 2016, 150p.

FOLHARINI, Saulo de Oliveira; VIEIRA, António; BENTO-GONÇALVES, António. Severidade dos incêndios florestais nos distritos do norte de Portugal (Porto, Vila Real, Braga, Bragança e Viana do Castelo) no período 2013 - 2016 utilizando o índice NBR. In: ENCONTRO LUSO-AFRO-AMERICANO DE GEOGRAFIA FÍSICA E AMBIENTE, 2. 2018, Guimarães. Atas [...]. Guimarães: CEGOT-UMinho, 2011. p. 1127-1134.

FUNCEME, Calendário das Chuvas no Estado do Ceará. 2020. Disponível em: https://bit.ly/3b1Yw0V Acesso em: 25 mar 2020.

GALLO, Juliano; OLIVEIRA JUNIOR, Raimundo Cosme de. Avaliação das classes de capacidade de uso das terras das comunidades Cuieiras, Carmelino, Itapeuá e Arimum da Resex Verde para Sempre, município Porto de Moz, PA. Espaço Científico, Santarém, v. 11, n. 1, p. 55-79, 2010.

GAO, B.-C. NDWI - A Normalized Difference Water Index for remote sensing of vegetation liquid water from space. Remote Sens. Environ., v. 58, p. 257-266, 1996.

IPCC, Summary for Policymakers. In: Shukla P.R. et al. Climate Change and Land: an IPCC special report on climate change, desertification, land degradation, sustainable land management, food security, and greenhouse gas fluxes in terrestrial ecosystems. 2019. Disponível em: https://bit.ly/317NWCw Acesso em: 27 abr. 2020.

IPECE. Perfil Municipal 2017 Farias Brito. Fortaleza: IPECE, 2018. 18 p. Disponível em: https://bit.ly/2CUeWgR Acesso em: 27 abr. 2020.

KARASIAK, Nicolas. Dzetsaka Qgis Classification plugin, 2016. Disponível em: https://github.com/nkarasiak/dzetsaka Acesso em: 17 abr. 2020. 
KEELEY, Jon E.. Fire intensity, fire severity and burn severity: a brief review and suggested usage. : a brief review and suggested usage. Int J Wildland Fire, Victroria, v. 18, n. 1, p. 116-126, jan. 2009. doi: http://dx.doi.org/10.1071/wf07049.

KEY, Carl H.; BENSON, Nathan C. Measuring and remote sensing of burn severity: the CBI and NBR. 1999. Disponível em: https://bit.ly/3bVhB6b Acesso em: 25 fev. 2020.

KEY, Carl H.; BENSON, Nathan C. Landscape Assessment (LA). In: LUTES, Duncan C. et al. FIREMON: Fire Effects Monitoring and Inventory System. Fort Collins: USDA Forest Service, 2006. p. LA-1-55.

LANDIS, J. Richard; KOCH, Gary G. The Measurement of Observer Agreement for Categorical Data. Biometrics, Washington, ano 1977, v. 33, n. 1, p. 159-174, mar. 1977. DOI 10.2307/2529310. Disponível em: www.jstor.org/stable/2529310. Acesso em: 27 abr. 2020.

LAW, Kin Hang; NICHOL, Janet. Topographic Correction for Differential Illumination Effects on Ikonos Satellite Imagery. In: ISPRS CONGRESS, 20. 2004, Istanbul. Proceedings [...]. Istanbul: ISPRS, 2004. p. 641-646. Disponível em: https://bit.ly/2SqMEPu. Acesso em: 21 abr. 2020.

MELO, Felippe Pessoa de. Risco ambiental e ordenamento do território em GaranhunsPE. 2016. 246 f. Tese (Pós-Graduação em Geografia) - Universidade Federal de Sergipe, São Cristóvão, 2016.

MORAIS, José Carlos Mendes de. Principais causas dos incêndios florestais e queimadas. 2. ed. Brasília: Ibama/Prevfogo, 2011. 35 p.

PARKS, Sean; DILLON, Gregory; MILLER, Carol. A New Metric for Quantifying Burn Severity: the relativized burn ratio. Remote Sens, Basel, v. 6, n. 3, p. 1827-1844, 27 fev. 2014. MDPI AG. doi: http://dx.doi.org/10.3390/rs6031827.

PONZONI, Flávio Jorge; SHIMABUKURO, Yosio Edemir; KUPLICH, Tatiana Mora. Sensoriamento remoto da vegetação. 2. ed. atual. e aum. São Paulo: Oficina de Textos, 2012. 176 p. ISBN 978-85-7975-053-3.

RIBEIRO, João Paulo Fernandes Márcico; BAPTISTA, Gustavo Macedo de Mello. Análise da Severidade de Queimadas na Amazônia por meio de dados Hiperespectrais. In: SIMPÓSIO BRASILEIRO DE SENSORIAMENTO REMOTO, 17. (SBSR), 2015, João Pessoa. Anais [...]. São José dos Campos: INPE, 2015. p. 477-484. 
RODRIGUES, Antônio. Incêndio em Farias Brito já destrói área de 12 hectares, na serra. Diário do Nordeste, 28 set. 2012. Disponível em: https://glo.bo/2xApfUq. Acesso em: 5 maio 2020.

RODRIGUES, Antônio. Incêndio já dura quatro dias na Serra do Quincuncá, em Farias Brito. Diário do Nordeste, 13 out. 2016. Disponível em: https://glo.bo/2W6nZ51. Acesso em: 5 maio 2020.

ROSAN, Thais Michele; ALCÂNTARA, Enner. Detecção de áreas queimadas e severidade a partir do índice espectral $\triangle$ NBR. In: SIMPÓSIO BRASILEIRO DE SENSORIAMENTO REMOTO, 17. (SBSR), 2015, João Pessoa. Anais [...]. São José dos Campos: INPE, 2015. p. 526-533.

ROY, David P.; BOSCHETTI, Luigi; TRIGG, Simon N. Remote Sensing of Fire Severity: assessing the performance of the normalized burn ratio: Assessing the Performance of the Normalized Burn Ratio. Ieee Geosci Remote S, New York, v. 3, n. 1, p. 112-116, jan. 2006.

SANTOS, Humberto Gonçalves dos et al. O novo mapa de solos do Brasil: legenda atualizada. 1. ed. Rio de Janeiro: Embrapa Solos, 2011. 67 p. ISBN 1517-2627. Disponível em: https://bit.ly/3d850g6. Acesso em: 27 abr. 2020.

SEEG, Sistema de estimativa de emissões de gases de efeito estufa. 2020. Disponível em: http://plataforma.seeg.eco.br/total_emission\#. Acesso em: 06 abr. 2020.

SILVA, Sheila Lopes da; BAPTISTA, Gustavo Macedo de Mello. Análise do Grau de Severidade de Áreas Queimadas na Estação Ecológica de Águas Emendadas por Meio de Dados do Landsat 8. Revista Brasileira de Geografia Física, [S.1.], v. 8, n. 2, p. 431-438, dez. 2015. ISSN 1984-2295. Disponível em: https://bit.ly/3c1pzKU. Acesso em: 21 abr. 2020. SILVA, Brenner Stefan Gomes; VALERIANO, Dalton de Morisson. Correção atmosférica e topográfica de imagens de satélite em terrenos montanhosos. In: SIMPÓSIO BRASILEIRO DE SENSORIAMENTO REMOTO, 12. (SBSR), 2005, Goiânia. Anais [...]. São Paulo: INPE, 2005. p. 3587-3594.

VEDOVATO, Laura Barbosa et al. Detection of burned forests in Amazonia using the Normalized Burn Ratio (NBR) and Linear Spectral Mixture Model from Landsat 8 images. In: SIMPÓSIO BRASILEIRO DE SENSORIAMENTO REMOTO, 17. (SBSR), 2015, João Pessoa. Anais [...]. São José dos Campos: INPE, 2015. p. 2984-2991. 